Таким образом, лингвокраеведение обладает богатейшим дидактическим потенциалом. Обращение к лингвокраеведческому материалу на уроках родного языка в школе активизирует познавательные интересы учащихся, создает положительный эмоциональный фон обучения.

$$
* * *
$$

1. Касаткин Л.Л. Русская диалектология. М., 2005. 283 с.

2. Ковалев Г. Ф. Ономастические исследования и изучение родного края // Воронежское лингвокраеведение. Межвузовский сборник научных трудов. Воронеж, 2005. №1. С.13-23.

3. Ковалев Г.Ф. Задачи лингвокраеведения в средней школе // Актуальные проблемы изучения и преподавания русского языка и литературы: сборник научных статей. Воронеж: Изд-во ВГПУ, 1996. С. 20-24.

4. Морева Н.А. Современная технология учебного занятия М.: Просвещение, 2007. 158 с.

5. Плешкова Т.Н. Бережное отношение к материнскому языку // Русская словесность. 2003. № 1. С. 41-45.

6. Филатова В.Ф. Лингвокраеведческая работа в школе // Воронежский краевед. Выпуск 1. Воронеж: ВГУ, 1991. С. 161-172.

\title{
Сербина Л.И., Чехонацкая А.В. \\ Методические аспекты применения цифровых образовательных ресурсов в процессе самостоятельной работы при обучении математике
}

ГБОУ ВО «Ставропольский государственный педагогический институт» (Россия, Ставрополь)

doi: 10.18411/lj-04-2021-169

\section{Аннотация}

Рассмотрены основные принципы самостоятельной работы и отличительные ее особенности организации при обучении математике. Обсуждается вопрос о использовании цифровых образовательных ресурсов как одного из методов повышающего эффективность реализации самостоятельной работы и самоконтроля знаний по математике. Проведен анализ современных цифровых образовательных ресурсов по математике и указаны их существенные методики особенности,

Ключевые слова: теория обучения, навыки самообразования, обязательная самостоятельная работа, самоконтроль, цифровые образовательные ресурсы, управляемые самостоятельные работы, тестирование, инновационные методы обучения.

\section{Abstract}

The basic principles of independent work and its distinctive features of the organization in teaching mathematics are considered. The issue of the use of digital educational resources as one of the methods that increases the effectiveness of the implementation of independent work and self-control of knowledge in mathematics is discussed. An analysis of modern digital educational resources in mathematics is carried out and their essential techniques are indicated, features,

Keywords: learning theory, self-education skills, compulsory independent work, selfcontrol, digital educational resources, guided independent work, testing, innovative teaching methods.

Обучение в широком смысле слова - это процесс формирования готовности обучаемых к определенной самостоятельной деятельности на основе вновь приобретенного знания и индивидуального практического опыта. Процесс обучения представляет собой не только систему сообщения и усвоения определенных знаний, но также не менее значимую систему формирования познавательных способностей и 
последовательного развития активной мыслительной деятельности обучающихся. В теории обучения и, соответственно для учебного процесса, существенно важным аспектом является вести учащихся «от незнания к знанию, от неумения к умению». Для успешного решения этой задачи крайне важно научить обучаемых самостоятельному овладению знаниями.

Хорошо известно, что формирование и развитие навыков самообразования и самостоятельной работы начинается в общеобразовательной школе. Как показывает практика, все изучаемые школьные дисциплины своим содержанием, присущей им логикой, методикой и дидактикой обучения, так или иначе, влияют на становление личности. Привитие учащимся навыков самостоятельной работы и непрерывного самообразования в процессе обучения всегда является одной из главных задач на каждом этапе школьного обучения. Система образования должна быть способна не только дать обучающимся знания, но и формировать потребность в непрерывном самостоятельном овладении умениями и навыками самообразования, а также самостоятельным и творческим подходом к знаниям на протяжении всей жизни [5]. В.И. Загвязинский, утверждал, что именно самостоятельная работа обучающихся «формирует готовность к самообразованию, создает базу непрерывного образования» в условиях быстрого обновления знаний [1].

Следует отметить, что самостоятельная работа является одной из важных и широко обсуждаемых проблем в школьном обучении. Отчасти это объяснимо тем, что в теории обучения единого определения понятия «самостоятельная работа» не существует. Так, для одних - это форма учебной работы и метод организации обучения, для других - это специальные задания, направленные для самостоятельного выполнения, для третьих - деятельность учащихся, которая протекает без непосредственного участия учителя. В школьном обучении математике, самостоятельная работа, определяемая в педагогическом словаре [2] как "деятельность обучающегося в процессе обучения, которую он выполняет по заданию педагога под его руководством, но без его непосредственного участия" является наиболее распространенной и эффективной формой самостоятельной учебной деятельности. По мнению многих педагогов, самостоятельная работа по математике представляет собой метод обучения, который повышает активность обучающихся, обеспечивает основательное усвоение учебного материала и является одним из самых действенных факторов, которые развивают личность [6].

Организация учебного процесса в школе при обучении математике складывается из различных видов и форм учебной деятельности, включая самостоятельную работу. В зависимости от целей, которые ставятся при выполнении самостоятельной работы по математике, обычно выделяют следующие задачи ее организации:

1) организация работы с учащимися по самообразованию;

2) формирование умений и навыков самостоятельной работы;

3) повышение уровня самоорганизации и самоконтроля;

4) вовлечение обучающихся в активную творческую деятельность.

Существенная роль в эффективной организации школьного обучения математике принадлежит классификации самостоятельной работы:

- по степени самостоятельности учащихся;

- по степени индивидуализации;

- по дидактическим целям обучения;

- по источнику знаний.

В процессе обучения математике на уроках и на внеурочных занятиях, применяются различные виды обязательной самостоятельной работы, которые организуются как во время индивидуальных, так и в групповых школьных занятиях. Наиболее естественным и эффективным видом самостоятельной деятельности учащихся при обучении математике является выполнение устных и письменных 
заданий. В процессе самостоятельной работы при выполнении различных упражнений закрепляются математические понятия, вырабатываются вычислительные навыки, приобретается умение геометрических построений, развивается пространственное представление.

Весьма распространенным видом самостоятельной работы при обучении математике является обязательная самостоятельная работа. Основными элементами этого вида самостоятельной работы, которая должна быть обязательно выполнена как своеобразный минимум, гарантирующий овладение фундаментальными математическими знаниями и практическими навыками решения примеров и задач, являются:

— наличие цели самостоятельной работы;

- наличие конкретного задания;

— четкое определение формы выражения результата самостоятельной работы;

- обязательность выполнения ее каждым учащимся, получившим задание.

Обязательная самостоятельная работа по математике имеет разнообразные формы, но чаще всего находит свое выражение в виде самых различных домашних заданий. В процессе самостоятельного выполнения домашнего задания учащиеся повторяют и закрепляют приобретенные на уроке знания, умения и навыки. Самостоятельное выполнение домашних работ по математике способствует развитию логического мышления, формирует чувство ответственности и навыки самообразования [4].

Особое внимание при этом следует уделить объему и характеру содержания домашних заданий. Как известно, учебные задания, в соответствии с требуемым для их выполнения уровнем самостоятельной деятельности учащихся, разделяют:

- на задания репродуктивного типа;

- на задания реконструктивного типа;

- на задания вариативного типа.

Для того, чтобы строить процесс обучения в соответствии с требованиями, отражающими общие закономерности школьного процесса обучения, необходимо на всех этапах обучения математике использовать различные виды и типы самостоятельных заданий. При важно помнить, что не следует переносить центр тяжести обучения на выполнение самостоятельных домашних заданий, как это иногда бывает. Однако, по мере накопления знаний и совершенствования методики проведения урока, необходимо повышать творческий характер самостоятельной домашней работы и совершенствовать формы, в которых она задается.

Одним из важных факторов, обеспечивающих успешную самостоятельную деятельность учащихся при обучении математике, является самоконтроль, основное назначение которого заключается в своевременном предотвращении или обнаружение уже сделанных ошибок. Формирование самоконтроля процесс непрерывный, осуществляемый под руководством учителя на всех стадиях процесса самостоятельной работы. Установлено, что существует прямая связь между уровнем самостоятельности учащихся при выполнении самостоятельной работы и степенью овладения ими самоконтролем усвоений знаний.

Одним из важных способов организации эффективного самоконтроля при выполнении самостоятельных работ является активное использование цифровых образовательных ресурсов. Цифровые образовательные ресурсы - это совокупность данных в цифровом виде, применимая для использования в учебном процессе [7]. Цифровые ресурсы, применяемые сегодня в деятельности человека, позволяют преодолевать барьеры традиционного обучения: темп освоения программы, выбор педагога, форм и методов обучения [3]. 
Особое место цифровые образовательные ресурсы занимают в процессе организации самостоятельной работы на уроках математики, Их использование при выполнении самостоятельной работы, в сочетании с традиционными методами обучения, повышает качество усвоения учащимися нового материала, предоставляя широчайшие возможности для создания разнообразных заданий по математике, в традиционной и инновационной формах. Так, например, в рамках использование в процессе обучения цифровых образовательных ресурсов при организации самостоятельной работы широко применяются, так называемые управляемые самостоятельные работы, позволяющие учащимся осуществлять самоконтроль в процессе их выполнения. Использование цифровых образовательных ресурсов и информационно-коммуникационных технологий значительно усиливает роль и значимость методов тестирования, превращая его в один из важных способов обучения, a также эффективного контроля и самоконтроля. Компьютерное тестирование позволяет проверить уровень математических знаний всех учащихся в короткий срок.

Очевидно, что модернизация методики организации самостоятельной работы за счет активного использования цифровых образовательных ресурсов позволяет при уменьшении часов, отведенных на аудиторные занятия, значительно увеличить количество часов на самостоятельную работу. В результате того, что использование цифровых учебных ресурсов и онлайн-продуктов в процессе обучения становится возможным за пределами аудитории, позволяя учиться в любом месте и в любое время, оно является уже не пассивным, как это было ранее, а активным средством обучения.

Такой подход в методике организации самостоятельной работы и учебной деятельности в целом, предоставляя возможность гибко сочетать урочные и внеурочные формы обучения, способствует процессу оптимизации самообразования и формирует у обучающихся навыки самостоятельного приобретения знаний и умений, которые так необходимы в процессе непрерывного образования.

Существующая практика применения цифровых учебных ресурсов в обучении математике уже вполне доказала, что они развивают у обучающихся способность конструктивного и логического мышления: способность рассуждать, анализировать, доказывать, задавать вопросы, давать четкие ответы, выдвигать конструктивные решения. Стала вполне очевидна роль цифровых технологий и учебных ресурсов в повышении ценности и качества процессов обучения и самообразования. Однако, обучение в условиях информатизации общества и интенсивного применения цифровые образовательные ресурсы, предъявляет новые требования к методике организации самостоятельной работы обучающихся. Поэтому продолжается активная работа по разработке, апробации и использованию цифровых образовательных ресурсов в преподавании математики в образовательных учреждениях.

В последнее время активно реализуется процесс создания и применения в обучении открытых онлайн ресурсов, начиная от отдельных заданий, тестов до полномасштабных курсов (модулей) по формированию необходимых компетенций. Обучающиеся и педагоги имеют доступ ко все большему количеству информационных технологий, цифровых ресурсов. Проведенный анализ особенностей цифровых образовательных ресурсов и их методических особенностей, данные которого представлены в таблице 1, показывает, что все существующие цифровые образовательные ресурсы условно можно разделить на две группы:

- цифровые ресурсы, требующие установки на компьютер, т.е. программное обеспечение;

- онлайн-ресурсы, не требующие установки на компьютер и работающие через браузер.

Следует заметить, что в организации самостоятельной работы и самообразования наиболее широко используются именно онлайн-сервисы, поскольку 
их не надо устанавливать на компьютер, а следовательно они не занимают на нем место в оперативной памяти.

Таблица 1.

\begin{tabular}{|c|c|}
\hline Название & Краткое описание методических возможностей \\
\hline \multicolumn{2}{|r|}{ Цифровые образовательные ресурсы, требующие установки на ПК } \\
\hline Microsoft Teams & $\begin{array}{l}\text { Цифровая платформа, разработанная компанией Microsoft, объединяющая в } \\
\text { себе чат, аудио и видео конференции, заметки и вложения. Позволяет не } \\
\text { только проводить онлайн-встречи, но и проводить тесты и выкладывать } \\
\text { задания в виде документа, таблицы или презентации, или можно загрузит } \\
\text { готовое из OneDrive или компьютера. }\end{array}$ \\
\hline \multicolumn{2}{|r|}{ Цифровые образовательные онлайн-ресурсы } \\
\hline $\begin{array}{c}\text { Российская } \\
\text { электронная школа }\end{array}$ & $\begin{array}{l}\text { Портал «Российская электронная школа» позволяет самостоятельно } \\
\text { ознакомится с теоретическим материалом по всем учебным предметам } \\
\text { школьного курса с последующим контролен уровня усвоения учебного } \\
\text { материала в виде прохождения тестов и контрольных заданий. }\end{array}$ \\
\hline ЯКласс & $\begin{array}{l}\text { Ресурс ориентирован на педагогов, учащихся и родителей. ЯКласс } \\
\text { интегрирован с электронными журналами, сотрудничает с популярными } \\
\text { издательствами. Содержит 1,6 трлн заданий школьной программы и } 1500 \\
\text { видеоуроков. Все материалы соответствуют ФГОС. }\end{array}$ \\
\hline СберКласс & $\begin{array}{l}\text { СберКласс - цифровая среда для коммуникации и взаимодействия основных } \\
\text { участников образовательного процесса относительно учебных целей. } \\
\text { Платформа становится инструментом организации учебного процесса: } \\
\text { учитель получает возможность для управления персонализированными } \\
\text { планами большого числа учеников, дает постоянную обратную связь об их } \\
\text { успехах, позволяет учителю развивать собственные компетенции. }\end{array}$ \\
\hline Google Classroom & $\begin{array}{l}\text { Бесплатный веб-сервис для школ, который призван упростить создание, } \\
\text { распространение и оценку заданий безбумажным способом. Основная цель } \\
\text { Google Класс - упростить процесс обмена файлами между учителями и } \\
\text { учениками. }\end{array}$ \\
\hline Online Test Pad & $\begin{array}{l}\text { Бесплатный многофункционалный сервис для проведения тестирования и } \\
\text { обучения. Online Test Pad позволяет создавать тесты с различными } \\
\text { вариантами ответов, опросы, кроссворды, диалоги, а так же уроки по любым } \\
\text { предметам. }\end{array}$ \\
\hline Quizizz.com & $\begin{array}{l}\text { Quizizz.com - сервис для создания онлайн-тестов и викторин, с возможностю } \\
\text { синхронного и асинхронного прохождения. Результаты по каждому заданию } \\
\text { отображаются в режиме реального времени. С помощью сервиса можно } \\
\text { задать домашнее задание с ограничением по времени выполнения. }\end{array}$ \\
\hline
\end{tabular}

Для успешного использования цифровых образовательных ресурсов при организации самостоятельной работы на уроках математики, необходимо:

— изучение особенностей цифровых образовательных ресурсов;

- ознакомиться с их содержанием и методическими возможностями;

— выбрать необходимый учебный материал;

- структурировать учебный материал по разделам;

— выбрать типы заданий;

- применять интерактивные информационные обучающие системы;

— комплектовать иллюстративный ряд, графические изображения.

Как показывает опыт, такой метод организации обязательной самостоятельной работы заставляет учащихся активно включаться в работу, пробуждает интерес к изучаемому материалу. Однако, необходимо понимать, что применение цифровых учебных ресурсов - это не самоцель, а инструменты, позволяющие лишь активизировать учебную деятельность учащихся, ресурсы призванные помогать интересно и доступно объяснять математические понятия, решать различные задачи, осуществлять самоконтроль и контролировать знания учащихся. Поэтому, при использовании цифровых учебных ресурсов в организации обязательной самостоятельной работы обучаемых следует четко определить цели и задачи ее выполнения, последовательность и способ изложения учебного материала, способ 
подачи информации, продумать доступность и целостность изложения материалов урока, достаточность методических комментариев, набор упражнений, средств контроля и самоконтроля.

Таким образом, использование в школьном обучении цифровых учебных ресурсов и технологий становится объективной необходимостью. Их всестороннее и продуманное применение в процессе обучения математике позволяет повысить эффективность традиционных методов организации самостоятельной работы. Важно, что при этом самостоятельная работа в контексте цифровизации образования является не только формой организации учебного процесса, но и становится основой формирования качественно новой теорией обучения, способствующей эффективному овладению методами самообразования и стимулирующей познавательную активность.

\section{$* * *$}

1. Загвязинский В. И. Теория обучения: Современная интерпретация: Учебное пособие для студентов вузов, - М: Академия, 2001. - 192 с.

2. Коджаспирова Г. М., Коджаспиров А.Ю. Словарь терминов по общей и социальной педагогикеПедагогический словарь. -М.: Академия. 2005. - 327 с.

3. Никулина, Т. В., Стариченко, Е.Б. Информатизация и цифровизация образования: понятия, технологии, управление / Т.В. Никулина, Е.Б. Стариченко // Педагогическое образование в России. - 2018. - №8. C. 107-113.

4. Сербина Л.И., Лазаренко В.С. Контекстное обучение как средство формирования универсальных учебных действий обучающихся старших классов// Вопросы педагогики - 2020 №4-4. С. 270-274.

5. Сербина Л. И., Губайдуллина Е. Ю. Особенности организации процесса изучения производной в школьном курсе алгебры и математического анализа в обучающей среде MOODL. // Modern Science - 2020, № 4-4, - C. 242-245.

6. Смирнова О. Ю. Теоретические аспекты самостоятельной работы обучающихся в контексте информатизации образования / Проблемы современного педагогического образования. - Сборник научных трудов: - Ялта: РИО ГПА, 2017. - Вып. 55. - Ч. 1. - С. 284-295.

7. Шагиева А.К. ЦИФРОВЫЕ ОБРАЗОВАТЕЛЬНЫЕ РЕСУРСЫ // Материалы VII Международной студенческой научной конференции «Студенческий научный форум» URL: https://scienceforum.ru/2015/article/2015008033 (дата обращения: 10.03.2021).

\section{Смирнова С.И. \\ Алгоритмическая деятельность как средство мотивации младших школьников к изучению математики}

Петрозаводский государственный университет (Россия, Петрозаводск)

doi: 10.18411/lj-04-2021-170

\section{Аннотация}

В статье рассматривается возможность повышения мотивации младших школьников к учению и интереса к изучению математики посредством работы над алгоритмизацией вычислительной деятельности.

Ключевые слова: алгоритм, мотивация, вычислительная деятельность, интерес к изучению математики.

\section{Abstract}

The article considers the possibility of increasing the motivation of primary school students to learn and interest in studying mathematics by working on the algorithmization of computational activities.

mathematics.

Keywords: algorithm, motivation, computational activity, interest in studying 